\title{
Risk Evaluation of Lightning Damage to Wind Turbines with the Electro-Geometrical Method
}

\author{
Tadashi Sakata Member (Kinden Corporation, sakata_tadashi@kinden.co.jp) \\ Kazuo Yamamoto Member (Kobe City College of Technology, kazuo@kobe-kosen.ac.jp) \\ Shozo Sekioka Member (Shonan Institute of Technology, sekioka@elec.shonan-it.ac.jp) \\ Shigeru Yokoyama Senior Member (CRIEPI, yokoyama@criepi.denken.or.jp)
}

Keywords: striking distance, lightning striking angle, distribution of lightning current, equivalent collection area

The electro-geometrical method (EGM) has been adopted for lightning protection design of transmission lines. The expected frequency at which that the conductors will be damaged by lightning can be calculated by the following equations.

$$
\left.\begin{array}{l}
\mathrm{N}_{\mathrm{F}}=\mathrm{N}_{\mathrm{g}} \mathrm{A}_{\mathrm{e}} \\
\mathrm{A}_{\mathrm{e}}=\int_{\mathrm{I}_{\min }}^{\mathrm{I}_{\max }} \mathrm{a}_{\mathrm{e}}(\mathrm{I}) \frac{-\mathrm{dP}(\mathrm{I})}{\mathrm{dI}} \mathrm{dI}
\end{array}\right\}
$$

where $\mathrm{N}_{\mathrm{g}}$ is the ground flash density per $\mathrm{m}^{2}$ per year; $\mathrm{a}_{\mathrm{e}}(\mathrm{I})$, the collection area on the ground surface; $\mathrm{A}_{\mathrm{e}}$, the equivalent collection area; and $\mathrm{P}(\mathrm{I})$, the cumulative distribution of the peak value of the lightning current.

In the case of transmission lines, the exposed surface is considered to be cylindrical. However, it should be mainly considered to be spherical in the case of wind turbines, as shown in Fig. 1.

The lightning stroke does not always occur in the vertical direction with respect to the plane of the ground. We assumed the lightning striking angle in three dimensional space to simplify the calculation of the equivalent collection areas, as shown in Fig. 2.

The distributions of the peak value of the lightning current mentioned in various documents are based on observational results of the

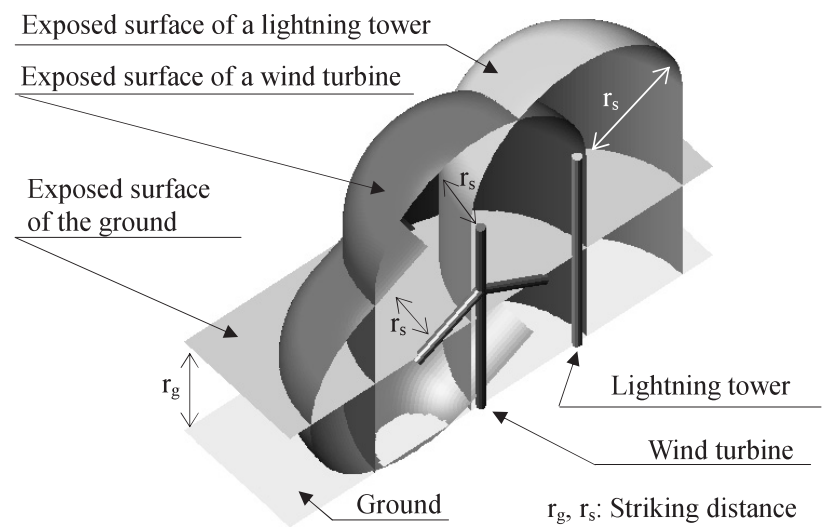

Fig. 1. Exposed surface
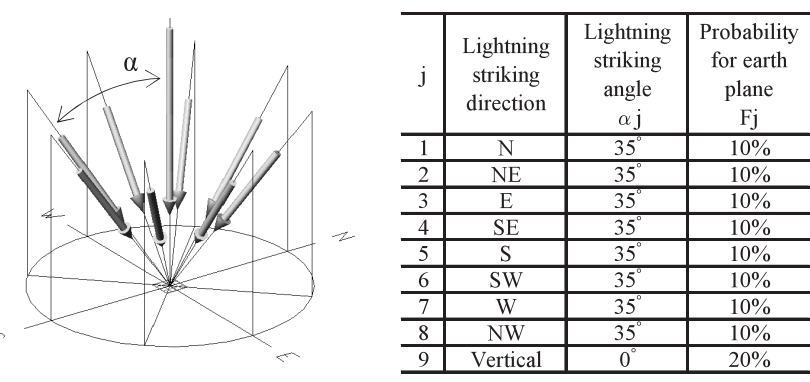

Fig. 2. Assumed lightning striking angle lightning that has struck structures. These distributions are different from those corresponding to lightning strokes from a thundercloud to the ground surface. We estimated the peak value of the current for all lightning strokes from a thundercloud to the ground surface by using the EGM, as shown in Fig. 3.

Observational results of the lightning strokes to a wind turbine and a lightning tower at Uchinada wind generation site on the coast of the Sea of Japan has been reported. We compared the calculated result with the observational results, using the observed data at the Uchinada site.

Figure 4 shows the comparison between the calculated and observation results. According to the comparison, the expected rate of lightning stroke seems to be reasonably good.

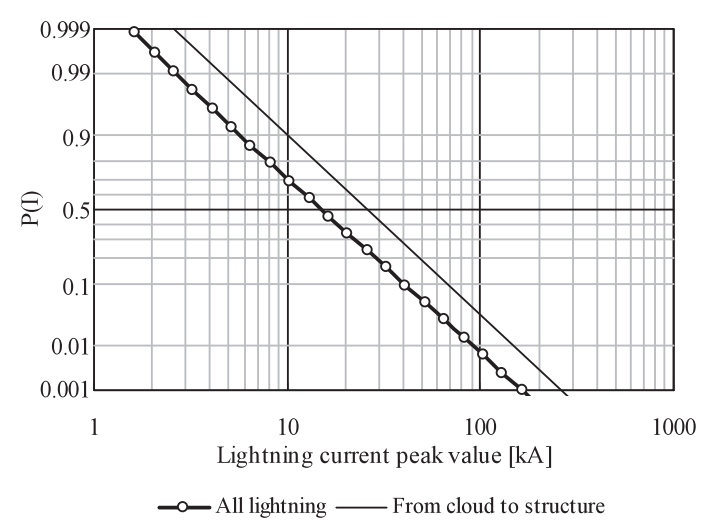

Fig. 3. Estimated cumulative distribution used by EGM

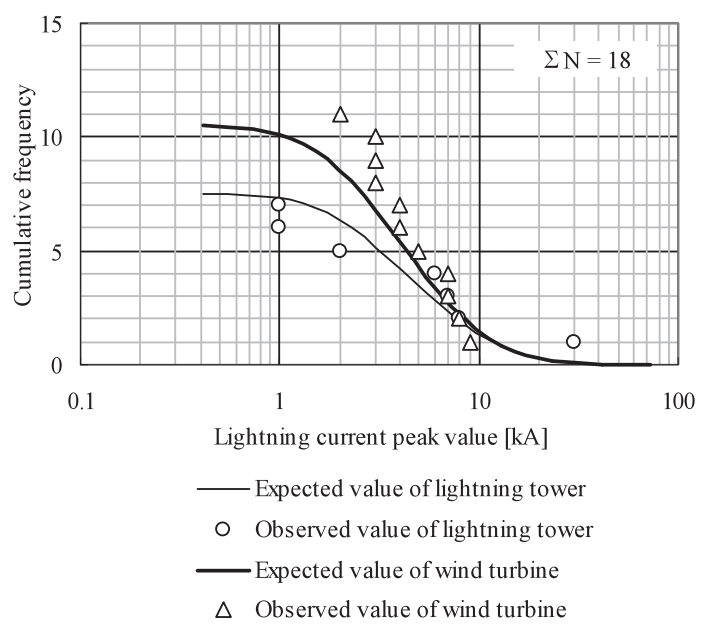

Fig. 4. Comparison of calculated and observational results 


\title{
Risk Evaluation of Lightning Damage to Wind Turbines with the Electro-Geometrical Method
}

\author{
Tadashi Sakata* Member \\ Kazuo Yamamoto** Member \\ Shozo Sekioka** Member \\ Shigeru Yokoyama**** Senior Member
}

The electro-geometrical method (EGM) has been adopted for lightning protection design of transmission lines. In this paper, probability calculations of direct lightning strokes to wind turbines are carried out by using the EGM. The distributions of the peak values of lightning current mentioned in various documents are based on observational results of lightning strokes onto structures. These distributions are different from those corresponding to lightning strokes from a thundercloud to the surface of the ground. Therefore, we have estimated the peak value of the lightning current and the probability of shielding failure by using the EGM. In addition, the equivalent collection areas of structures were calculated on the basis of an assumed lightning striking angle in three-dimensional space.

Keywords: striking distance, lightning striking angle, distribution of lightning current, equivalent collection area

\section{The Electro-geometrical Method}

The electro-geometrical method (EGM) has been adopted for lightning protection design of transmission lines. According to this method, a relation exists between the striking distance and the lightning current. This relation can be expressed as follows ${ }^{(1)(2)}$ :

$$
\left.\begin{array}{l}
\mathrm{r}_{\mathrm{s}}(\mathrm{I})=\mathrm{AI}^{\mathrm{b}} \\
\mathrm{r}_{\mathrm{g}}(\mathrm{I})=\mathrm{k}_{\mathrm{g}} \mathrm{r}_{\mathrm{s}}(\mathrm{I})
\end{array}\right\}
$$

where $r_{s}(I)$ is the striking distance from a conductor; $r_{g}(I)$, the striking distance from the ground; $\mathrm{A}, \mathrm{b}$, and $\mathrm{k}_{\mathrm{g}}$, the coefficients; and I, the peak value of the lightning current.

According to Fig. 1, which illustrates the EGM, the exposure arc is determined from the lightning current and the positional relation between the conductors and the ground. The maximum value of the lightning current, $\mathrm{I}_{\max }$, is related to the striking distance, assuming that the lightning does not strike a conductor, and the minimum value, $I_{\min }$, is related to the overvoltage that the transmission line must withstand.

The statistical distribution of the lightning current can be considered to be a logarithmic normal distribution. The following equation provides the probability $\mathrm{P}$ that the actual value $\mathrm{i}$ is greater than or equal to the lightning current $\mathrm{I}^{(1)}$.

\footnotetext{
* Kinden Corporation

3-41, Honjohigashi 2-chome, Kita-ku, Osaka 531-8550

** Kobe City College of Technology

8-3, Gakuenhigashi-machi, Nishi-ku, Kobe 651-2194

*** Shonan Institute of Technology

1-1-25, Tsujido-Nishikaigan, Fujisawa 251-8551

**** Central Research Institute of Electric Power Industry (CRIEPI)

2-6-1, Nagasaka, Yokosuka 240-0190
}

$$
\left.\begin{array}{l}
\mathrm{P}(\mathrm{i} \geq \mathrm{I})=1-\frac{1}{\sqrt{2 \pi} \sigma_{\log \mathrm{i}}} \int_{-\infty}^{\log \mathrm{I}} \exp \frac{-\left(\mathrm{x}-\mu_{\log \mathrm{i}}\right)^{2}}{2 \sigma_{\log \mathrm{i}}^{2}} \mathrm{dx} \\
\mathrm{X}=\log \mathrm{i}
\end{array}\right\}
$$

where $\sigma_{\text {logi }}$ is the standard deviation of $\log \mathrm{i}$, and $\mu_{\operatorname{logi}}$ is the average value of $\log \mathrm{i}$.

The expected frequency at which that the conductors will be damaged by lightning can be calculated by the following equations.

$$
\left.\begin{array}{l}
\mathrm{N}_{\mathrm{F}}=\mathrm{N}_{\mathrm{g}} \mathrm{A}_{\mathrm{e}} \\
\mathrm{A}_{\mathrm{e}}=\int_{\mathrm{I}_{\min }}^{\mathrm{I}_{\max }} \mathrm{a}_{\mathrm{e}}(\mathrm{I}) \frac{-\mathrm{dP}(\mathrm{I})}{\mathrm{dI}} \mathrm{dI}
\end{array}\right\}
$$

where $\mathrm{N}_{\mathrm{g}}$ is the ground flash density per $\mathrm{m}^{2}$ per year; $\mathrm{a}_{\mathrm{e}}(\mathrm{I})$, the collection area on the ground surface; and $A_{e}$, the equivalent collection area.

The equivalent collection area of a structure is defined as the area of ground surface that has the same annual frequency of direct lightning flashes as that of the structure ${ }^{(3)}$. Furthermore, the collection area is related to not only the lightning

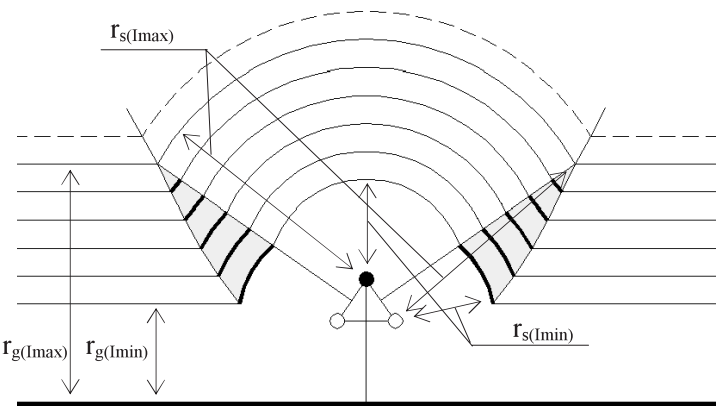

Fig. 1. Exposure arc of the conductors and the ground 


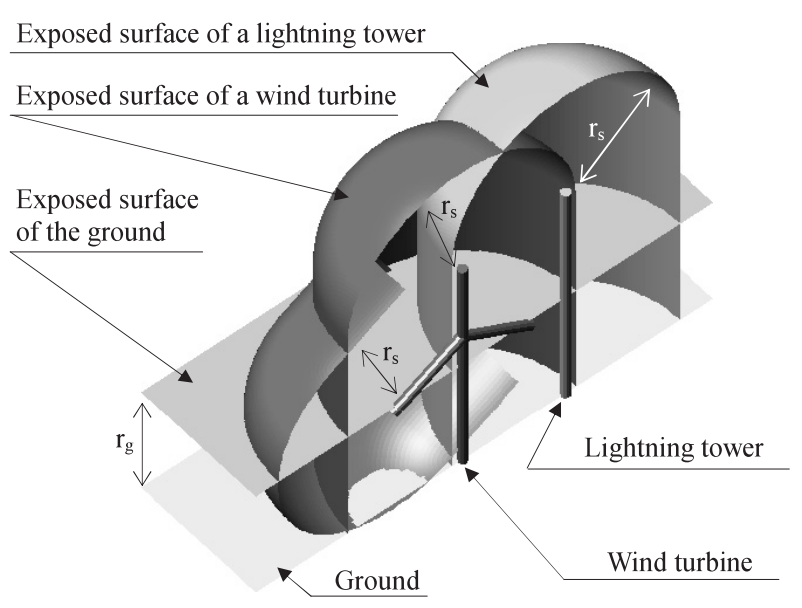

Fig. 2. Exposed surface

current but also the lighting striking angle, as mentioned later.

\section{The EGM in the Case of Wind Turbines}

In the case of transmission lines, the exposed surface ${ }^{(4)(5)}$ is considered to be cylindrical. However, it should be mainly considered to be spherical in the case of wind turbines.

According to Fig. 2, the exposed surface changes due to not only the lightning current but also the direction and orientation of the blades. It is necessary to calculate the equivalent collection areas considering all the situations and probabilities. However, such a study would be time consuming. Therefore, in this paper, we assumed that each of the cases (1)-(4) shown in Fig. 3 has a $25 \%$ probability. We then calculated the equivalent collection areas by using the following equation.

$$
\mathrm{A}_{\mathrm{e}}=0.25 \sum_{\mathrm{i}=1}^{4} \mathrm{~A}_{\mathrm{ei}}
$$

where $A_{e i}$ is the equivalent collection area in each situation.

\section{Lightning Striking Angle in Three-dimensional Space}

The lightning stroke does not always occur in the vertical direction with respect to the plane of the ground. According to the EGM, the probability distribution of the lightning striking angle in the case of transmission lines is assumed to be given by the following equation ${ }^{(1)}$.

$$
\left.\begin{array}{l}
\mathrm{f}(\alpha)=\mathrm{K}_{\mathrm{m}} \cos ^{\mathrm{m}} \alpha \\
\mathrm{K}_{\mathrm{m}}=\frac{1}{\int_{-\pi / 2}^{\pi / 2} \cos ^{\mathrm{m}} \alpha \mathrm{d} \alpha}
\end{array}\right\}
$$

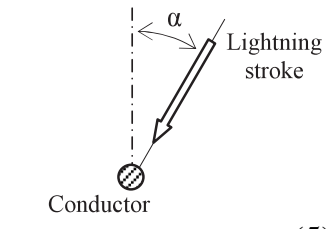

Here, $\alpha$ is the lightning striking angle in the vertical section, and $m$ is a fixed number.

In the case of wind turbines, the lightning striking angle in three-dimensional space should be considered because the exposed surface is spherical and not cylindrical. As shown in Fig. 4, we assumed the lightning striking angle in threedimensional space to simplify the calculation of the equivalent collection areas.

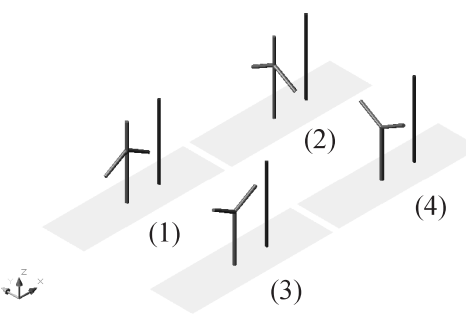

Fig. 3. Directions and orientations of blades

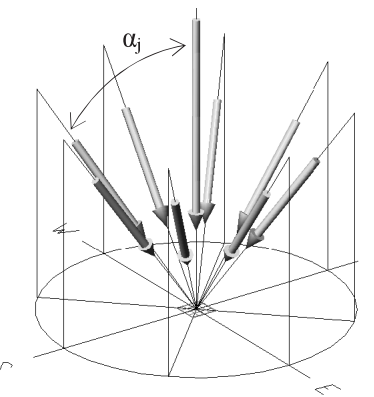

\begin{tabular}{c|c|c|c}
\hline $\mathrm{j}$ & $\begin{array}{c}\text { Lightning } \\
\text { striking } \\
\text { direction }\end{array}$ & $\begin{array}{c}\text { Lightning } \\
\text { striking } \\
\text { angle } \\
\alpha \mathrm{j}\end{array}$ & $\begin{array}{c}\text { Probability } \\
\text { for earth } \\
\text { plane } \\
\mathrm{Fj}\end{array}$ \\
\hline 1 & $\mathrm{~N}$ & $35^{\circ}$ & $10 \%$ \\
\hline 2 & $\mathrm{NE}$ & $35^{\circ}$ & $10 \%$ \\
\hline 3 & $\mathrm{E}$ & $35^{\circ}$ & $10 \%$ \\
\hline 4 & $\mathrm{SE}$ & $35^{\circ}$ & $10 \%$ \\
\hline 5 & $\mathrm{~S}$ & $35^{\circ}$ & $10 \%$ \\
\hline 6 & $\mathrm{SW}$ & $35^{\circ}$ & $10 \%$ \\
\hline 7 & $\mathrm{~W}$ & $35^{\circ}$ & $10 \%$ \\
\hline 8 & $\mathrm{NW}$ & $35^{\circ}$ & $10 \%$ \\
\hline 9 & Vertical & $0^{\circ}$ & $20 \%$ \\
\hline
\end{tabular}

Fig. 4. Assumed lightning striking angles
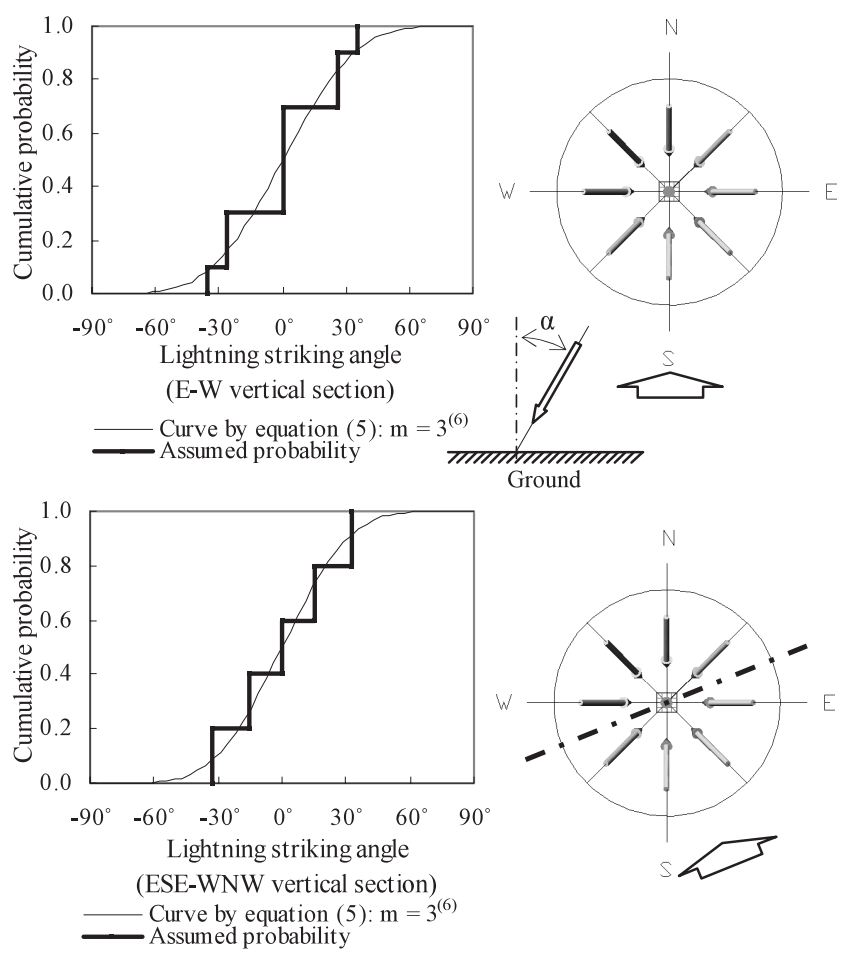

Fig. 5. Comparison of cumulative probability

We converted the assumed probability distribution into a vertical section distribution and compared it with the distribution given by Eq. (5). According to Fig. 5, which shows the result of the conversion, the difference does not seem to be significant.

\section{Calculation of Equivalent Collection Area}

The equivalent collection area can be found comparatively easily because the lightning striking angle is considered in only nine directions. The equivalent collection area can be calculated by using the following equations. 


$$
\left.\begin{array}{l}
\left.\mathrm{A}_{\mathrm{e}}=0.25 \sum_{\substack{\mathrm{i}=1 \\
\mathrm{a}}}^{4} \sum_{\mathrm{j}=1}^{9} \mathrm{~F}_{\mathrm{j}} \int_{-\infty}^{\infty} \mathrm{a}_{\mathrm{eij}}(\mathrm{I}) \frac{-\mathrm{dP}(\mathrm{I})}{\mathrm{dI}} \mathrm{dI}\right) \\
\mathrm{a}_{\mathrm{eij}}(\mathrm{I})=\frac{\mathrm{I})}{\cos \alpha_{\mathrm{j}}}
\end{array}\right\}
$$

where $\mathrm{i}$ is the suffix of the position of a blade, as shown in Fig. 3 ; j, the direction of the lightning stroke, as shown in Fig. $4 ; F_{j}$, the probability of the assumed lightning striking direction for the ground plane, as shown in Fig. 4; $\mathrm{a}_{\mathrm{eij}}$, the collection area of a structure; $\mathrm{a}_{\mathrm{pij}}$, the projected area of the exposed surface; $\alpha_{\mathrm{j}}$, the lightning striking angle, as shown in Fig. 4.

Figure 6 shows the relation between an exposed surface, its projected area, and its collection area.

Although it is possible to calculate the projected areas, in this paper, we drew exposed surfaces by using a CAD software to measure the projected areas. Figure 7 illustrates an example of the exposed surfaces, as seen from the direction of propagation of lightning, and Fig. 8 shows the projected areas.

The value of the projected area can be determined from

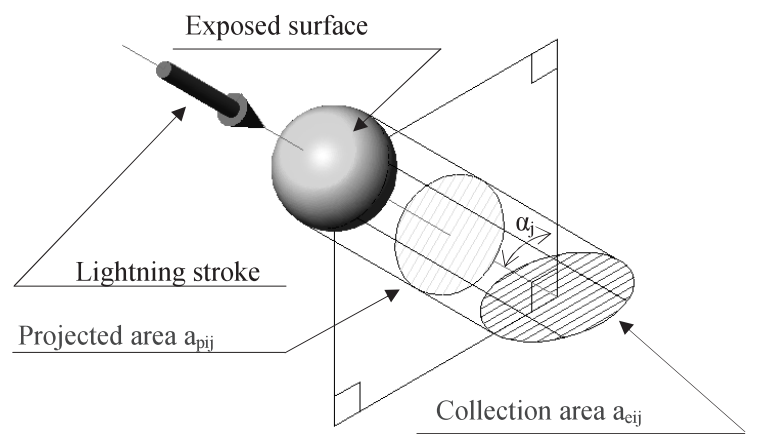

Fig. 6. Projected area and collection area

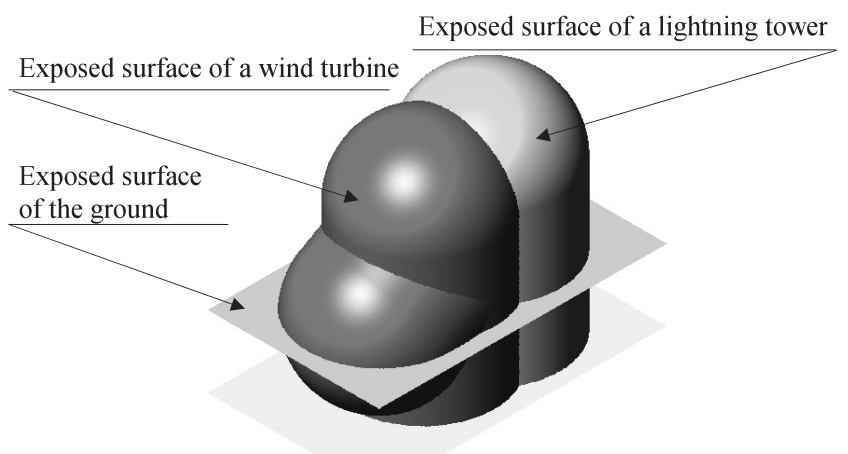

Fig. 7. Example of exposed surfaces

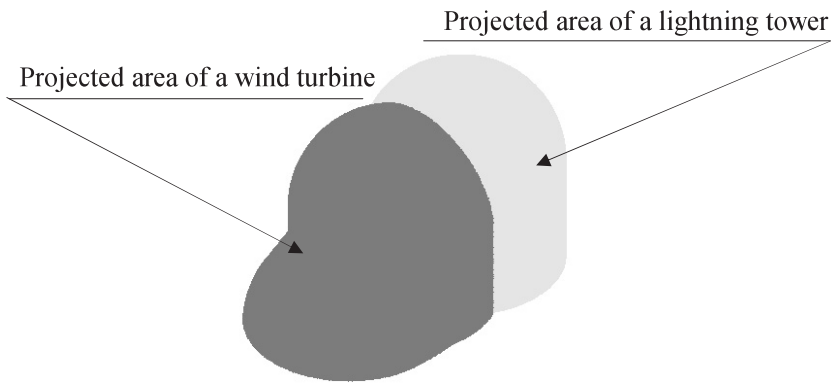

Fig. 8. Example of projected areas
Fig. 8, and Eq. (6) provides the value of the equivalent collection area.

\section{Distribution of the Peak Value of the Lightning Current}

The distributions of the peak value of the lightning current mentioned in various documents are based on observational results of the lightning that has struck structures. These distributions are different from those corresponding to lightning strokes from a thundercloud to the ground surface because lightning tends to strike a structure when the value of the lightning current is high, as shown in Fig. 9. Therefore, we estimated the peak value of the current for all lightning strokes from a thundercloud to the ground surface by using the EGM.

For the estimation of the peak value of the current distribution for all the lightning strokes from thunderclouds to the ground surface, we adopted the distribution given by Eq. (7) as the distribution of the lightning from the thunderclouds to the structures ${ }^{(1)}$. Moreover, we used the approximated distribution as shown in Fig. 10 to simplify the integration calculation.

In addition, we adopted Eq. (8) for calculating the striking distance $^{(7)}$.

$$
\begin{aligned}
& \frac{-\mathrm{dP}(\mathrm{I})}{\mathrm{dI}}=\frac{1}{\sqrt{2 \pi} \sigma_{\log \mathrm{i}}} \exp \frac{-\left(\mathrm{x}-\mu_{\log \mathrm{i}}\right)^{2}}{2 \sigma_{\log \mathrm{i}}^{2}} \\
& \mathrm{x}=\log \mathrm{i} \\
& \mu_{\log \mathrm{i}}=1.415(26 \mathrm{kA}) \\
& \sigma_{\log \mathrm{i}}=0.325 \\
& \left.\begin{array}{l}
\mathrm{r}_{\mathrm{s}}(\mathrm{I})=10 \mathrm{I}^{0.65} \\
\mathrm{r}_{\mathrm{g}}(\mathrm{I})=\mathrm{r}_{\mathrm{S}}(\mathrm{I})
\end{array}\right\} \ldots \ldots \ldots \ldots \ldots \ldots \ldots \ldots \ldots \ldots \ldots \ldots \ldots
\end{aligned}
$$

Figures 11 and 12 show the estimated result of the distribution of the peak value of the current for all the lightning

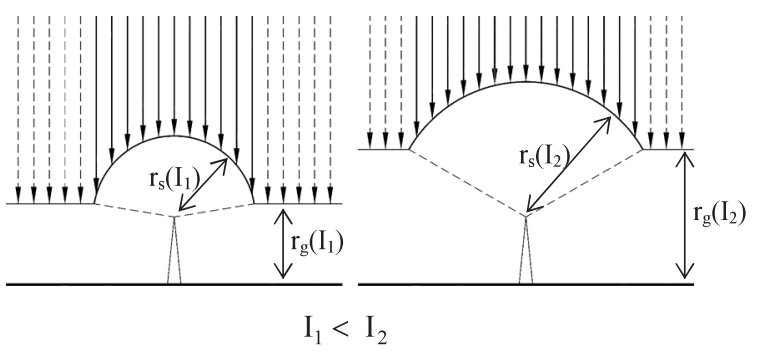

Fig. 9. Comparison of exposure arcs

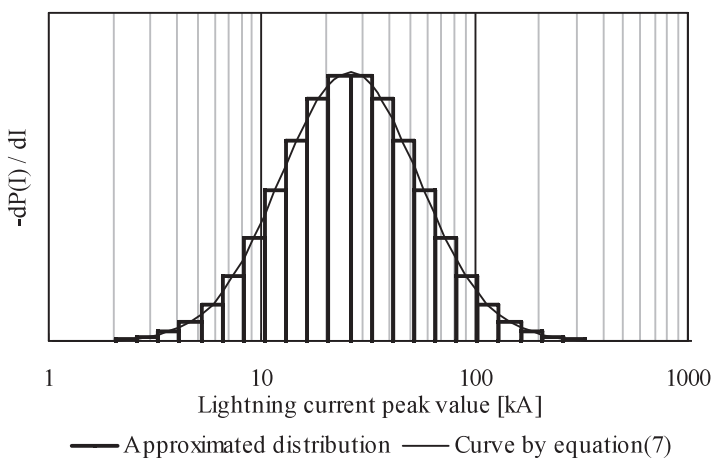

Fig. 10. Distribution according to Eq. (7) and approximated distribution 


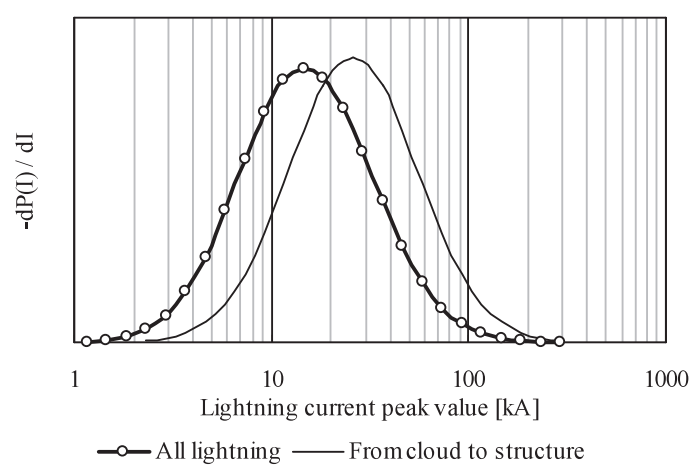

Fig. 11. Estimated density distribution used by the EGM

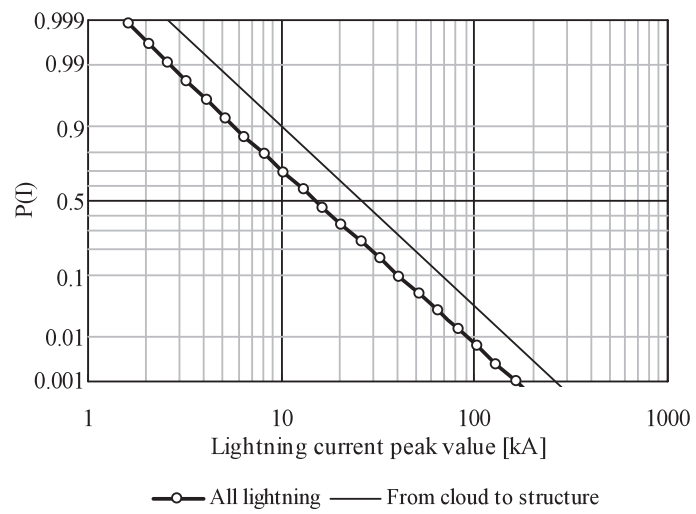

Fig. 12. Estimated cumulative distribution used by the EGM

strokes from thunderclouds to the ground. This estimated distribution shifts to the lower-current side, and the difference in the median values is about $11 \mathrm{kA}$.

\section{Comparison with the Observational Result}

Observational results of winter lightning striking a wind turbine and a lightning tower at Uchinada wind generation site on the coast of the Sea of Japan has been reported by S. Minamimura et al. ${ }^{(8)(9)}$. Figure 13 shows the arrangement of the Uchinada site, which is composed of a wind turbine and a lightning tower. The heights of the wind turbine and the lightning tower are $100.25 \mathrm{~m}$ and $104.99 \mathrm{~m}$, respectively. The lightning tower stands $45.5 \mathrm{~m}$ to the northwest of the wind turbine. We compared the calculated result with the observational results, using the observed data at the Uchinada site.

It has been reported that the current characteristics of winter lightning on the coast of the Sea of Japan are different from those of summer lightning. In addition, the probability of lightning strokes in the winter season greatly depends on the direction from which the thundercloud approaches.

We removed half data observed during a period of strong winds to reduce the influence of the direction of thundercloud movement from all observed data at the Uchinada site. Figure 14 shows the distribution of the peak value of the lightning currents, which we extracted and assumed an examination object. Figure 15 shows the estimated result of the distribution of the peak value of the current for all the lightning strokes from thunderclouds to the ground used in the EGM.

Figure 16 shows an equivalent collection area for every position of the blades shown in Fig. 3. The equivalent collection

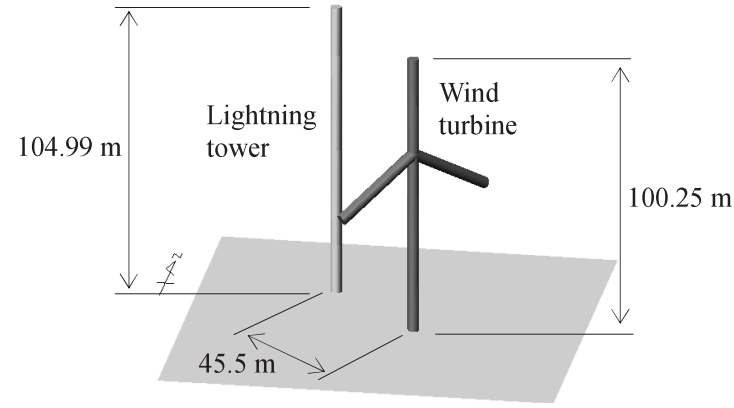

Fig. 13. Arrangement of Uchinada site

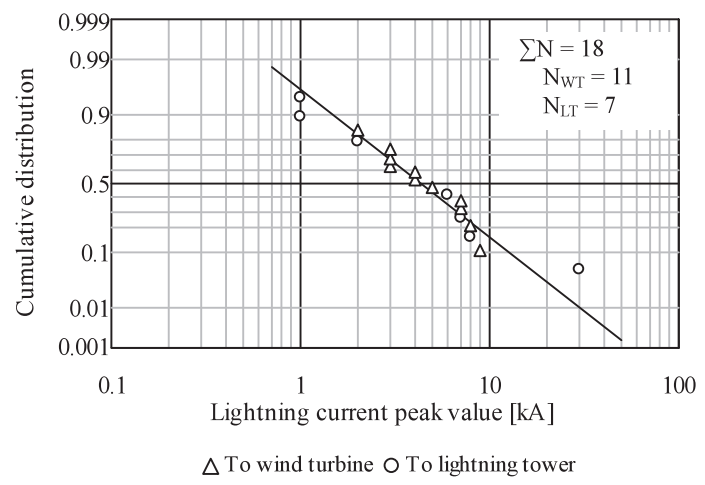

Fig. 14. Lightning strokes at Uchinada site

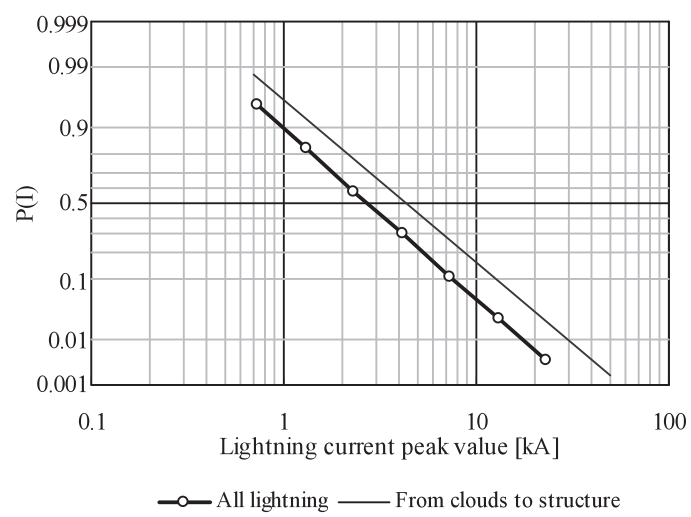

Fig. 15. Estimated cumulative distribution at Uchinada site

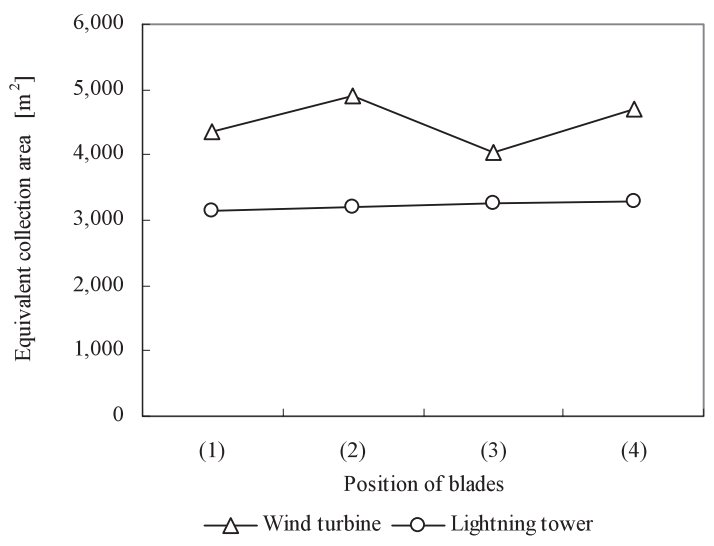

Fig. 16. Equivalent collection area 


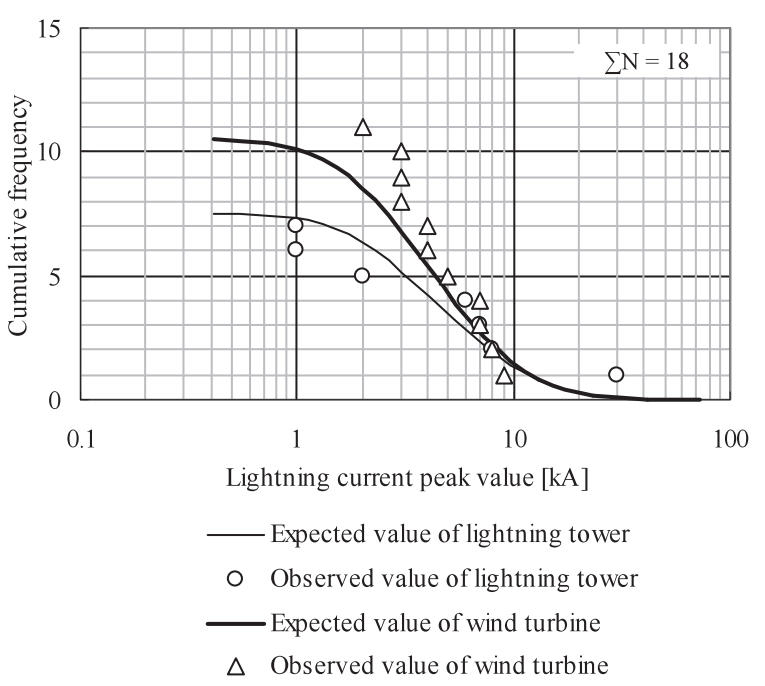

Fig. 17. Comparison of calculated and observational results

area of a wind turbine varies somewhat due to a change in the position of its blades.

In addition, if the blades are stopped when a thundercloud approaches, the probability of lightning striking the wind turbine has a minimum value at position (3).

Figure 17 shows a comparison between the calculated and observational results. According to the comparison, the expected rate of lightning strokes seems to be reasonably good. However, it is necessary to consider that a considerable number of upward lightning strokes are included in the lightning observed at the Uchinada site.

Recently, the EGM has been adopted as a method for lightning protection design of transmission lines, including upward lightning ${ }^{(1)}$. We think that the favourable results obtained in this study suggest the possibility for the use of the EGM in lightning shielding examinations, including upward lightning, in three-dimensional space. Therefore, it will be necessary to collect many data and to check the possibility for the use of the EGM as a method for lightning protection design in three-dimensional space in the future.

\section{Conclusions}

The EGM has been adopted for lightning protection design of transmission lines. In this paper, probability calculations of direct lightning strokes to wind turbines have been carried out by using the EGM, considering a wind turbine as a structure in three-dimensional space. Although there are still some issues to be considered, the probability calculation results at the Uchinada site appear to be good. In addition, the results suggest the possibility of adopting the EGM to lightning protection design, including protection against upward lightning on a wind turbine.

(Manuscript received March 26, 2007, revised June 18, 2007)

\section{References}

( 1 ) Subcommittee for Transmission Lines, Lightning Protection Design Committee: "Guide to lightning protection design for transmission lines", CRIEPI Rep, T72 (2003)
( 2 ) H.R. Armstrong and E.R. Whitehead: "Field and analytical studies of transmission line shielding", IEEE Trans. Power Apparatus Syst., Vol.87, No.1, pp.270-281 (1968)

( 3 ) IEC TR 61400-24, Wind Turbine Generator Systems-Part 24: Lightning protection (2002)

( 4 ) T. Horváth: "Interception of lightning air termination systems constructed with rolling sphere method", Proc. 2006 International Conference on Lightning Protection, pp.555-560 (2006)

( 5 ) "Protection against lightning electromagnetic impulse-Part 1: General principles", IEC 1312-1 (1995)

(6) Sectional Committee for Transmission Lines, Lightning Protection Design Study Committee: "Lightning Proof Design Guide-Book for Transmission Lines", CRIEPI Rep, 175031 (1976)

( 7 ) JIS A 4201, Protection of structures against lightning (2003)

( 8 ) S. Minamimura, M. Hashimoto, and H. Sakurano: "Observation of Winter Lightning Discharge at Uchinada Wind Power Station”, Proc. 2004 IEIEJ Annual Conference, pp.35-36 (2004)

(9) S. Minamimura, M. Hashimoto, and H. Sakurano: "Observation of Winter Lightning Discharge at Uchinada Wind Power Station (Part 2)", Proc. 2005 IEIEJ Annual Conference, pp.125-126 (2005)

Tadashi Sakata (Member) was born in Osaka, Japan, on June 7, 1955.

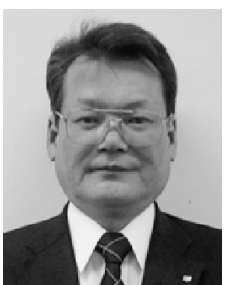
He graduated in electrical engineering from University of Osaka Prefecture in 1978. He has been working for Kinden Corporation since 1978. He is now engaged in electric power engineering.

Kazuo Yamamoto (Member) was born in Osaka, Japan in 1974. He

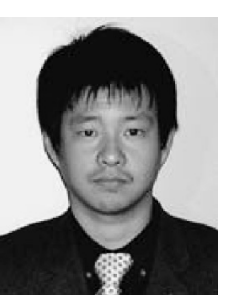
received his Bachelor's, Master's, and Doctoral degrees all in engineering from Doshisha University, Kyoto, Japan in 1997, 2000, and 2007 respectively. He had been with Nara National College of Technology from 2000 to 2005 . He has been an associate professor at Kobe City College of Technology since 2007. From 1998 to 1999 he was a Visiting Researcher at the Manitoba HVDC Research Centre, Winnipeg, Manitoba, Canada. His research interest includes lightning protection for wind turbine generation systems and surge analyses using electromagnetic field computations.
Shozo Sekioka

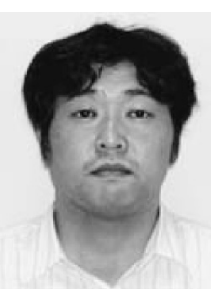

(Member) was born on December 30, 1963. He received the B.Sc. and Dr.Eng. degrees in electrical engineering from Doshisha University, Kyoto, Japan in 1986 and 1997, respectively. He joined Kansai Tech Corporation in 1987. He has been an associate professor at Shonan Institute of Technology since 2005 and has been engaged in the lightning surge analysis in electric power systems.
Shigeru Yokoyama (Senior Member) was born in Miyagi, Japan,

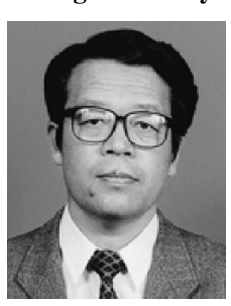
on March 5, 1947. He received the B.Sc, and $\mathrm{Ph}$. Ddegrees from the University of Tokyo, Japan, in 1969 and 1986, respectively. He joined Central Research Institute of Electric Power Industry, Tokyo, Japan, in 1969. Since then he has been engaged in the research of lightning protection on power systems, buildings and wind turbines. He holds posts of Executive Research Scientist at CRIEPI. He was Professor at Kyushu University since 2001 through 2007 . He was a vice president of the IEE Japan in 2001. He is a fellow of IEEE and a chairman of IEC TC81 Japanese committee. 